\title{
Posterior reversible encephalopathy syndrome presenting with atypical findings: case study
}

\author{
Rakhi Gaur ${ }^{1}$, Kalpana Thakur², Shiv Kumar Mudgal ${ }^{3 *}$
}

\begin{abstract}
${ }^{1}$ Department of Obstetrics and Gynecology, College of Nursing, All India Institute of Medical Sciences, Rishikesh, Dehradun, India

${ }^{2}$ Ph.D Scholar, College of Nursing, All India Institute of Medical Sciences, Rishikesh, Dehradun, India

${ }^{3}$ Department of Medical-Surgical Nursing, College of Nursing, All India Institute of Medical Sciences, Rishikesh, Dehradun, India
\end{abstract}

Received: 21 July 2019

Accepted: 30 August 2019

\section{*Correspondence:}

Dr. Shiv Kumar Mudgal,

E-mail: peehupari05@gmail.com

Copyright: (c) the author(s), publisher and licensee Medip Academy. This is an open-access article distributed under the terms of the Creative Commons Attribution Non-Commercial License, which permits unrestricted non-commercial use, distribution, and reproduction in any medium, provided the original work is properly cited.

\begin{abstract}
PRES (posterior reversible encephalopathy syndrome) is a syndrome characterized by headache, confusion, seizures and altered mental status. A 26 years old woman came to emergency department with a history of hypertension, blurred vision and seizures. She was diagnosed as a G3P2L1 at 29 weeks +1 day with IUGR with preeclampsia associated with deranged kidney functions later complicated by development of PRES. Patient underwent emergency LSCS and was kept on mechanical ventilator as condition worsened during immediate post-operative period. Dialysis was also done to regulate urea and creatinine levels. Patient was treated with anti-hypertensive, anti-epileptics, antibiotics, intravenous fluids and continuous monitoring of blood pressure. Patient's condition improved gradually, and her discharge was planned. PRES is a condition, if managed in initial phase can lead to early recovery and reduce mortality.
\end{abstract}

Keywords: Blurred vision, Deranged kidney function, Eclampsia, Focal seizures, Hypertensive retinopathy, Posterior reversible encephalopathy syndrome

\section{INTRODUCTION}

PRES (Posterior reversible encephalopathy syndrome) is a syndrome characterized by headache, confusion, seizures and altered mental status. Most of the time, it is accompanied by acute hypertension. ${ }^{1}$ There may be visual disturbances and status epilepticus or tonic-clonic seizures. The common location is parieto-occipito lobe or posterior lobe of brain. Areas of edema (swelling) are commonly seen on MRI. Symptoms may get resolved after sometimes although visual changes last for longer duration or forever. Although, PRES is considered as reversible condition, but it may cause permanent neurological damage in rare cases.

\section{CASE REPORT}

A 26 years old multi-gravida woman who is a referred case brought to emergency department with a history of hypertension (HTN), deranged kidney functions since past 3 years presented with gradually increasing headache associated with blurred vision from last 3-4 days, along with two episodes of generalized abnormal body movements which was accompanied by uprolling of eyeballs and jaw clenching and one episode of vomiting. Patient's family revealed the history of on and off headache, bilateral pedal edema and was on medication i.e. Atorvas and Arkamin since last 3 years after she had 
diagnosed with HTN during her last pregnancy and dead fetus was born with LSCS in 2016.

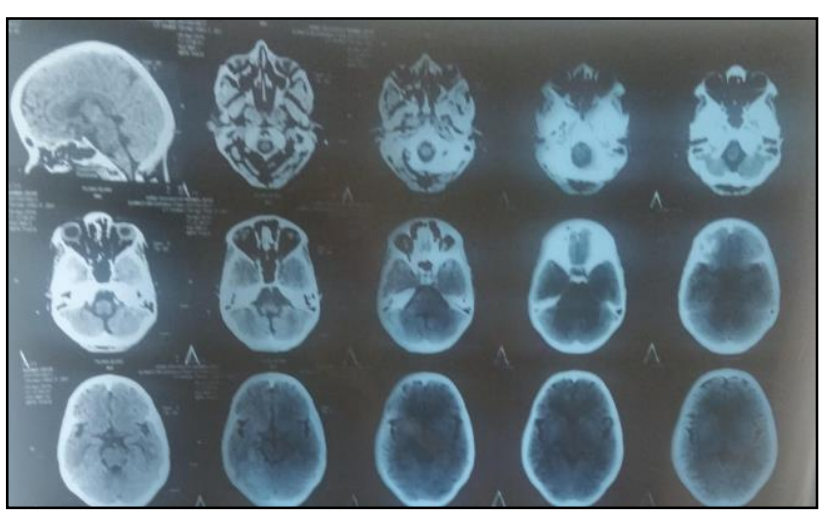

Figure 1: NCCT Brain depicting calcified granulomas are present in bilateral frontal lobes.

On her arrival to emergency department, her initial vital signs were: B.P $=170 / 120 \mathrm{~mm} / \mathrm{Hg}, \mathrm{HR}=88 / \mathrm{min}$. and Temperature $=98.6^{\circ} \mathrm{F}$. During initial examination, spontaneous conception was diagnosed by urine pregnancy test (UPT) which was later confirmed by ultrasonography (USG) for 8 months of gestation. After Obstetrics consultation, she was diagnosed as G3P2L1 at 29 weeks +1 day with IUGR with HTN superimposed with eclampsia.

In emergency department patient was treated with Labetalol, Dexamethasone and $\mathrm{MgSO}_{4}$. It was determined that an emergency LSCS may be needed to prevent fatal consequences and an emergency LSCS under GA was performed on $26^{\text {th }}$ April 2019 (on the day of admission) and she delivered a male baby with birth weight $869 \mathrm{gm}$ and APGAR which was ' 0 ' initially and later came out to be ' 4 '. Baby was admitted to NICU for close observation and further management. Unfortunately, patient was not able to come out of general anaesthesia and could not ventilate spontaneously. As an immediate treatment measures, she was shifted to ICU and kept on Mechanical ventilator. She was on SIMV mode (VC+PS) with GCS - 9 and infusion of Midazolam @ 2ml/hour and NTG @6ml/hour. She was also administered $\mathrm{MgSO}_{4}$ @ $0.5 \mathrm{ml} /$ hour and DNS @ 800ml/24hours.

\section{Investigations}

Haematological examination revealed that patient's total leukocyte counts $\left(26.33\right.$ thou $\left./ \mathrm{mm}^{3}\right)$, lymphocytes $(15.71 \%)$, red blood cells count $\left(2.758 \mathrm{mill} / \mathrm{mm}^{3}\right)$, Haemoglobin $(7.761 \mathrm{gm} / \mathrm{dl})$, hematocrit $(24.72 \%)$, mean corpuscular haemoglobin concentration $(31.4 \mathrm{~g} / \mathrm{dl})$, red cell distribution width $(15.31 \%)$ and mean platelet volume $(6.118 \mathrm{fL})$. Liver panel: LFT analysed alkaline phosphatise (467.4 U/L, serum protein (4.45 gm/dl). However, Kidney panel: KFT revealed that urea (112.56 $\mathrm{mg} / \mathrm{dl})$ and creatinine $(5.17 \mathrm{mg} / \mathrm{dl})$ levels were raised.
NCCT brain was done which reported that calcified granulomas are present in bilateral frontal lobes. There is presence of ill-defined white matter hypo-density in right parietal lobe with preserved grey matter along with white matter differentiation. Findings were suggestive for PRES syndrome (Figure 1). Ophthalmology consultation was done and found cotton wool spots in right eye and flame shaped haemorrhage in left eye which clearly depicts that patient had hypertensive retinopathy (Grade III).

\section{Management}

During initial $2^{\text {nd }}$ post-operative day, patient had altered sensorium and eventually developed focal seizures, had impaired urine output (20-25ml/hours). Urgent dialysis was done, and she was on drugs i.e. NTG, $\mathrm{MgSO}_{4}$, Labetalol, Midazolam, Mannitol and Fetanyl. She was extubated on 30 ${ }^{\text {th }}$ April 2019 as she could manage to ventilate spontaneously with oxygen therapy. Patient also developed post-ictal confusion and delirium due to renal causes and psychiatric consultation was done for the same. Tab. Resperidone (0.5mg HS) was prescribed. On $1^{\text {st }}$ May 2019 patient was capable enough to ventilate on room air and there was a slight change in her treatment. Ceftriaxone, Metrogyl, Pantop, Tranexa, Amlodepin, Lasix and Resperidone are the drugs given for further management. Patient was responding well to treatment and her condition improved gradually.

\section{DISCUSSION}

Posterior reversible encephalopathy syndrome PRES is a reversible neurotoxic state that happens secondary to the shortcoming of the posterior circulation to autoregulate in response to acute changes in vital sign (blood pressure). Hyper perfusion associated with interference of the blood brain barrier results in vasogenic swelling within the parieto-occipital regions, most of the time without infarction. ${ }^{1-3}$ One of the hallmark of this disease is its reversibility of symptoms. ${ }^{4}$ In few typical cases like coma, status epilepticus, patients may require intensive treatment and it may also lead to permanent neurological impairment or death in very rare cases. ${ }^{5,6}$

The cause of PRES is still a debatable matter, but most common hypothesis state that it occurs due to disruption of brain auto-regulation which is primarily caused by hypertension. Hyper-perfusion and cerebral vessel damage occurs as result of uncontrolled hypertension which further leads to vasogenic edema because of interstitial extravasation of proteins and fluids. ${ }^{3,4}$ Mean arterial pressures is an important parameter as increased MAP $>200 \mathrm{mmHg}$ may cause irreversible damage. Another hypothesis state that it occurs in case of systemic inflammatory state including sepsis, eclampsia, transplantation and auto-immune disease which causes endothelial damage. ${ }^{1-3}$ It can be stated here that further research is still needed to find out the exact cause and prevent this treatable yet threatening condition. In present 
case, patient had history of hypertension since last 3 years and also had previous history of eclampsia during the time of last childbirth.

It is considered as a syndrome as it includes group of symptoms like headache, visual disturbances, seizures, and altered consciousness, which are often associated with distinctive neuro-imaging findings of edema in affected areas of brain. ${ }^{2,3}$ The symptoms can vary from mild to severe in intensity like visual loss can progress to cortical blindness, retinal detachment and confusion or agitated client can go into coma. ${ }^{1,3,7}$ Sometimes, patient experience non-convulsive seizures like staring, eye blinking, or head turning. ${ }^{8,3}$ Acute hypertension is identified as a trigger for PRES, although patients may have other co morbidities as renal failure, autoimmune disturbances which increases the risk of PRES during pregnancy. ${ }^{1,3}$ It is common among women because the major causes of PRES is pre-eclampsia/eclampsia developed during pregnancy. ${ }^{6}$ Our patient presented with headache, blurred vision, two episodes of generalized tonic-clonic seizures and bilateral pedal edema. Clinical picture of our patient and computed tomography findings guided to a diagnosis of PRES. She developed focal seizures, retinopathy and post-ictal confusion in postoperative phase which was then managed actively to prevent further damage.

Stroke, demyelinating lesions of brain, stroke, cerebral venous thrombosis is some of the differential diagnosis of PRES. Computed tomography (CT) is not $100 \%$ sensitive for diagnosis of PRES, but it is commonly used for rapid assessment in case of emergency. In PRES and many other cases, CT imaging can be normal and therefore it is not reliable. ${ }^{7}$ MRI is helpful in differentiating vasogenic edema from cytotoxic edema that is why mostly preferred to make final diagnosis. ${ }^{9}$ For this patient, NCCT was done and findings reported presence of ill-defined white matter hypo-density in right parietal lobe with preserved grey matter along with white matter differentiation.

Prevention is always better than cure, early identification and diagnosis is the mandatory to prevent irreversible damage and long term complications. Screening for patients should be done for all patients with preeclampsia and HELP syndrome. Management of patient in early stage lead to faster recovery and patients' condition improve dramatically within few days or week. In case of PRES, it is important that how was patient dealt in acute phase for management.

Management of blood pressure is first priority in management and it is important to rule out the underlying pathology. ${ }^{1,7}$ Major goal of blood pressure management with intravenous anti-hypertensive therapy is not only to control blood pressure but also to decrease 20-25\% mean arterial pressure (MAP) during initial 2 hours of treatment. $6,7,10$ Patients with PRES may also require anaesthesia and ventilation in case of generalized status epileptics and airway management, anti-epileptic for management of seizures. Blood transfusion, administration of thiamine and management for impaired kidney functions including dialysis is also a part of standard treatment.

It is required to be sensitive while administering antihypertensives because quick reduction of blood pressure can cause impairment in cerebral perfusion pressure and promote ischemia. It is suggested that appropriate choice of anti-hypertensive drugs include labetalol, cardene, or fenoldopem. ${ }^{6,7}$ In present case, patient was treated with NTG initially along with $\mathrm{MgSO}_{4}$ and labetalol therapy. Patient was also given midazolam, mannitol and fetanyl for management of convulsions. It has been reported in many case studies that patient's condition improve quickly in response to anti-hypertensive, anti-epileptics and other supportive care and management. ${ }^{3,6,7}$

\section{CONCLUSION}

The patient described in this case was a woman with uncontrolled hypertension history and diagnosed with PRES. She was admitted to ICU as she was on continuous infusion of anti-hypertensives, anti-epileptics and management of airway. Later, she underwent dialysis and her condition improved rapidly. Patient became normal after two weeks of treatment and plan for discharge was initiated with follow-up in OPD.

Funding: No funding sources

Conflict of interest: None declared

Ethical approval: The study was approved by the Institutional Ethics Committee

\section{REFERENCES}

1. Roth C, Ferbert A. The posterior reversible encephalopathy syndrome: what's certain, what's new? $2019 . \quad$ Available at: https://www.ncbi.nlm.nih.gov/pubmed/21551107.

2. Bartynski W. Posterior reversible encephalopathy syndrome, part 2: controversies surrounding pathophysiology of vasogenic edema. Am J Neuroradiol. 2008;29(6):1043-9.

3. Hobson E, Craven I, Blank S. Posterior reversible encephalopathy syndrome: a truly treatable neurologic illness. Peritoneal Dialysis Int. 2012;32(6):590-4.

4. Kozak O, Wijdicks E, Manno E, Miley J, Rabinstein A. Status epilepticus as initial manifestation of posterior reversible encephalopathy syndrome. Neurol. 2007;69(9):894-7.

5. Servillo G, Striano P, Striano S, Tortora F, Boccella $\mathrm{P}$, De Robertis E, et al. Posterior reversible encephalopathy syndrome (PRES) in critically ill obstetric patients. Int Care Med. 2003;29(12):2323-6.

6. Legriel S, Azoulay E. Selection bias in analysis of status epilepticus in the intensive care unit. Critical Care Med. 2011;39(4):928. 
7. Mirzamoradi M, Hosseini MS, Saleh M, Esmaeili S. Posterior reversible encephalopathy syndrome (PRES) associated with eclampsia: a case study. Int $\mathbf{J}$ Med Res Health Sci. 2017;6(3):48-53.

8. Kaplan P. No, some types of nonconvulsive status epilepticus cause little permanent neurologic sequelae (or: "The cure may be worse than the disease »). Neurophysiol Clinique/Clinical Neurophysiol. 2000;30(6):377-82.

9. Chambers K, Wayne Cain T. Postpartum blindness. Annals Emerg Med. 2004;43(2):243-6.
10. Ramsay L, Williams B, Johnston G, MacGregor G, Poston L, Potter J, et al. Guidelines for management of hypertension: report of the third working party of the British Hypertension Society. J Human Hyper. 1999;13(9):569-92.

Cite this article as: Gaur R, Thakur K, Mudgal SK. Posterior reversible encephalopathy syndrome presenting with atypical findings: case study. Int J Reprod Contracept Obstet Gynecol 2019;8:4090-3. 